\title{
La creación de un departamento administrativo en la comunidad autónoma de las Illes Balears
}

\author{
Felio José Bauzá Martorell
}

Sumario: ABREVIATURAS.-I. CREACIÓN FORMAL. 1. Principio de autoorganización. A) Régimen jurídico. B) Naturaleza jurídica. 2. Competencia subjetiva. 3. Contenido objetivo de la competencia. A) Denominación y competencias. B) Competencias y funciones. C) Organización interna. 4. Instrumento de creación. 5. Nombramiento de titulares de órganos. A) Consejero. B) Secretario general y directores generales. C) Declaración de actividades y de bienes y derechos patrimoniales. 6. Apertura de centro de trabajo. - II. DISPONIBILIDAD PRESUPUESTARIA. 1. Rectificación de créditos. A) Competencia subjetiva e instrumento de creación. B) Creación de una sección presupuestaria. C) Gastos de personal. 2. Funcionamiento a través de otros órganos y unidades. A) Ejecución presupuestaria. B) Gastos de personal. C) Función interventora y gestión económica. D) Contabilización y liquidación del presupuesto.-III. RECURSOS HUMANOS. 1. Cambio de adscripción de puestos de trabajo. A) Escisión de un departamento. B) Traspaso de competencias. 2. Creación de puestos de trabajo. 3. Orden de funciones. A) Concepto y naturaleza jurídica. B) Procedimiento.-IV. PROCEDIMIENTO ADMINISTRATIVO. 1. Creación del registro de entrada y salida de documentos. 2. Régimen de suplencias. A) Entre miembros del Gobierno. B) Secretaría del Consejo de Gobierno. C) Órganos directivos. 3. Delegación de competencias y delegación de firma. 4. Bases reguladoras de subvenciones. A) Plan estratégico de subvenciones. B) Contenido de las bases. C) Procedimiento de elaboración de las bases.

\section{ABREVIATURAS:}

Art.: artículo.

BOCAIB: Boletín Oficial de la Comunidad Autónoma de las Islas Baleares.

BOE: $\quad$ Boletín Oficial del Estado.

BOIB: $\quad$ Butlletí Oficial de les Illes Balears.

CAIB: $\quad$ Comunidad Autónoma de las Illes Balears.

EAIB: $\quad$ Estatuto de autonomía de las Illes Balears, aprobado por Ley Orgánica 2/1983, de 25 de febrero, según redacción operada por Ley Orgánica 1/2007, de 28 de febrero.

Ext.: $\quad$ Extraordinario.

LOTC: $\quad$ Ley Orgánica 2/1979, de 3 de octubre, del Tribunal Constitucional.

LRJCAIB: Ley 3/2003, de 26 de marzo, de Régimen Jurídico de la Administración de la CAIB.

LRJPAC: $\quad$ Ley 30/1992, de 26 de noviembre, de Régimen Jurídico de las Administraciones Públicas y del Procedimiento Administrativo Común, reformada por Ley 4/1999.

Núm.: $\quad$ Número.

RPT: $\quad$ Relación de puestos de trabajo.

UGE: Unidad de gestión económica. 
La organización administrativa es una materia harto consolidada en los manuales de Derecho administrativo. A estas alturas hablar de la potestad organizatoria no permitiría elaborar una aportación ni siquiera tímida a los estudios publicados en torno a la LRJAE de 1957, a la Constitución vigente de 1978 en el contexto de la distribución de competencias entre el Estado y las Comunidades autónomas — nos referimos lógicamente al manido art. 149.1.18 - o más recientemente a la LOFAGE.

No obstante lo anterior, bien es cierto que la novación de la organización administrativa al inicio de una legislatura, o incluso la creación de un departamento a lo largo de la misma, se traduce invariablemente en un entramado de normas y actos de índole administrativa, presupuestaria, de función pública... que las más de las veces pasan desapercibidos en los manuales al uso.

En este sentido el presente estudio tiene por objeto abordar desde un punto de vista estrictamente práctico, el iter administrativo en que consiste la creación de una consejería, concretamente en la CAIB, desde el decreto de constitución de la misma, hasta su andadura en el entramado institucional (registro de entrada y salida de documentos, convocatoria de subvenciones...).

\section{CREACIÓN FORMAL}

\section{Principio de autoorganización}

El poder organizatorio - al decir del profesor VILLAR PALASí ${ }^{1}$ - hunde sus raíces en el principio de autonomía. En efecto, la autonomía político-legislativa que vertebra el actual Estado de las Autonomías Hace posible que - a imagen y semejanza de la división de poderes en el Estado - la organización institucional autonómica discurra entre el legislativo y el ejecutivo, siendo este último dirigido por el gobierno, que a su vez resulta auxiliado por el aparato instrumental que es la Administración.

En este sentido, si el principio de autonomía explica la existencia de una asamblea legislativa de la que nace - de acuerdo con el principio de legitimación democrática indirecta - un gobierno (elemento político) en calidad de órgano superior a la Administración (elemento administrativo), siendo el consejero la bisagra que enlaza uno y otro: el consejero es miembro del órgano político y, a su vez, cabeza departamental del principal y superior órgano en que se estructura la administración autonómica: las consejerías.

1 J.L. Villar Palasí, Apuntes de Derecho Administrativo. Parte General. Tomo I. Madrid, 1977. Pág. 215. 
En definitiva, el principio de autoorganización se regula al más alto nivel y se integra en el bloque de la constitucionalidad (art. 28 LOTC) toda vez el art. 79 EAIB, relativo a la administración propia, atribuye a la CAIB la creación y la organización de una administración propia, en el marco de los principios generales y de las normas básicas de la legislación del Estado y del Estatuto, que a su vez trae causa del art. 30.1 del mismo texto legal, que atribuye a la CAIB la competencia exclusiva sobre la organización, régimen y funcionamiento de sus instituciones propias.

\section{A) Régimen jurídico}

Más allá de las previsiones constitucionales y estatutarias, la creación de un departamento administrativo se rige por la Ley 3/2003, de 26 de marzo, de régimen jurídico de la Administración de la $\mathrm{CAIB}^{2}$, así como por la Ley 4/2001, de 14 de marzo, del Gobierno de la $\mathrm{CAIB}^{3}$.

En materia presupuestaria habrá que traer a colación el Decreto legislativo $1 / 2005$, de 24 de junio, por el que se aprueba el texto refundido de la Ley de finanzas de la $\mathrm{CAIB}^{4}$. Asimismo y por lo que a función pública respecta, resulta obligado atender a la Ley 3/2007, de 27 de marzo, de la Función Pública de la CAIB $^{5}$ y - supletoriamente - la Ley de Cortes Generales 7/2007, de 12 de abril. Del Estatuto Básico del Empleado Público ${ }^{6}$.

Por último, la confección de unas bases reguladoras de las subvenciones se fundamenta en el Decreto legislativo 2/2005, de 28 de diciembre, por el cual se aprueba el texto refundido de la Ley de Subvenciones ${ }^{7}$.

\section{B) Naturaleza jurídica}

A nadie escapa que la creación de una consejería en el seno del gobierno de una comunidad autónoma consiste en la creación de un órgano administrativo.

En efecto y en directa relación con la teoría de la personalidad jurídica, resulta obligado traer a colación la tradicional distinción entre entidad, órgano y

\footnotetext{
2 BOIB núm. 44, de 3 de abril de 2003; BOE num. 98, de 24 de abril de 2003.

3 BOIB núm. 35, de 22 de marzo de 2001; BOE núm. 86, de 10 de abril de 2004.

4 BOIB núm. 98, de 28 de junio de 2005; BOE núm. 240, de 7 de octubre de 2005.

5 BOIB núm. 49, de 3 de abril de 2007; BOE núm. 101, de 27 de abril de 2007.

6 BOE núm. 89, de 13 de abril de 2007.

7 BOIB núm. 196, de 31 de diciembre de 2005.
} 
unidad administrativa. En este sentido, si la Comunidad autónoma - como persona jurídica que es y, en consecuencia, titular de derechos y obligacionesreviste la cualidad de entidad y por ello goza - a tenor del art. 2 de la Ley 3/2003 - de personalidad jurídica, por el contrario una consejería participa de la naturaleza de órgano administrativo.

Cuando el art. 6 de la Ley 3/2003 atribuye al órgano administrativo la posibilidad de surtir efectos frente a terceros o la necesidad de actuar en el tráfico jurídico imperio legis, enumera dos características que se proyectan en toda su extensión sobre la consejería, estructura superior de la organización administrativa de la Comunidad autónoma, que comprende otros órganos jerárquicamente dependientes y que a su vez estos últimos integran unidades administrativas.

En este sentido la Ley de Régimen Jurídico en su art. 5 entiende que la Administración de la Comunidad autónoma está constitutita por órganos jerárquicamente ordenados y que - bajo la dirección superior del presidente y del Gobierno - la Administración de la CAIB se estructura en órganos superiores y órganos directivos. En su apartado tercero este precepto atribuye a los consejeros la cualidad de órganos superiores ${ }^{8}$.

No vamos a traer a colación en este punto la clásica teoría del órgano ni las reglas de imputación o representación que han discutido autores de la talla de JELLINEK o GIERKE en la doctrina iuspublicista alemana. Baste señalar que la naturaleza jurídica del órgano confiere a la consejería la cualidad de brazo ejecutor de la entidad Comunidad autónoma en el sentido de que esta última actúa a través de la consejería competente por razón de la materia, ya sea vertical u horizontal.

\section{Competencia subjetiva}

Desde el punto de vista subjetivo, la creación y extinción de consejerías es una competencia de dirección que el art. 11.c de la Ley 4/2001 atribuye al presidente de la Comunidad autónoma.

No puede ser de otra forma toda vez, en un sentido cronológico, la creación de una consejería al inicio de una legislatura se materializa en el momento inmediatamente posterior en que el presidente resulta investido y toma posesión.

En efecto, en este instante en el cuadro institucional coincide una asamblea legislativa recientemente constituida como consecuencia de un proceso

\footnotetext{
8 Posiblemente sería más acertado desde un punto de vista léxico atribuir tal consideración a la consejería, que es en puridad el órgano administrativo, y no al consejero, que en todo caso es el titular del órgano.
} 
electoral, que acaba de otorgarla confianza a uno de sus miembros para que asuma la presidencia de la Comunidad y forme gobierno. En ese momento y durante unas horas no existe gobierno, ni siquiera gobierno en funciones. El gobierno saliente ha cesado automáticamente con el cese del presidente saliente, hecho que se verifica con la toma de posesión del presidente entrante.

Por consiguiente el presidente se encuentra solo en el ejecutivo y sólo él puede crear los departamentos en que se estructure y organice el gobierno que va a formar.

El otro escenario - la creación de la consejería a lo largo de la legislatura y, como tal, existiendo gobierno - no altera para nada esta competencia subjetiva, ya sea por razones de derecho positivo, o bien porque la función de dirección y de organización del ejecutivo está residenciada en el presidente.

\section{Contenido objetivo de la competencia.}

\section{A) Denominación y competencias}

La creación de una consejería no se reduce a la decisión de contar con un departamento distinto, bien sea ex novo como consecuencia de una trasferencia del Estado, o ya sea por la refundición o escisión de funciones entre departamentos existentes.

El art. 11.c de la Ley 4/2001 atribuye al presidente la facultad directiva de creación y extinción de consejerías, así como la de establecer su denominación y sus competencias.

La denominación no ofrece duda alguna. La consejería deberá contar con una denominación, que hará referencia al sector o sectores de actividad administrativa funcionalmente homogéneos cuya competencia se le atribuya.

Respecto a este último punto, el instrumento de creación de la consejería deberá determinar el dato positivo de la competencia que ejerce.

\section{B) Competencias y funciones}

En este punto se plantea la problemática de la distinción entre competencias y funciones. Los decretos de creación de consejerías atribuyen al consejero competencias y en cambio residencian en los titulares de los órganos directivos funciones. 
En efecto, los decretos del presidente de las Illes Balears de creación de las consejerías de la VI Legislatura (2003-2007) ${ }^{9}$ con carácter general atribuyen competencias al consejero y funciones a secretarios y directores generales, con dos salvedades: al director general del gabinete técnico del presidente le atribuyen competencias y a la vicepresidenta del Gobierno le asignan funciones.

Por el contrario, el Decreto 11/2007, de 11 de julio, del Presidente de las Illes Balears, por el cual se establecen las competencias y la estructura orgánica básica de las consejerías de la Administración de la CAIB en la VII Legislatu$\mathrm{ra}^{10}$ no distingue entre competencias y funciones, sino que asigna competencias a las consejerías y a las direcciones generales, omitiendo cualquier referencia tanto a los titulares de estos órganos como a los secretarios generales por venir establecidas con carácter ordinario en la Ley 3/2003.

Esta distinción que efectúan los instrumentos de creación obliga a plantear si efectivamente competencias y funciones son atribuibles a órganos superiores y directivos respectivamente.

El profesor SANTAMARÍA PASTOR analiza en profundidad tanto el concepto de competencia como las modalidades de distribución de la misma en el seno de la potestad organizatoria. Para este autor competencia «es el conjunto de intereses - fines y materias - y de potestades encomendado por el sistema normativo a cada ente y a cada uno de los órganos que lo integran»11, de manera que no distingue entre personas jurídicas y órganos por lo que a la asignación de competencias se refiere.

No existe base que fundamente la distinción entre competencias y funciones entre unos órganos (los superiores) y otros (los directivos). $\mathrm{Si}-$ de acuerdo con la doctrina alemana - la competencia consiste en una función (ya sea normativa, ya sea meramente ejecutiva) sobre una determinada materia, lo que determina la competencia de un órgano será la materia cuya responsabilidad - reguladora o de gestión - se le atribuye, modulada por esa función más amplia o más reducida. Pero distinguir competencia y función entre órganos no tiene sentido, porque la segunda es la modulación que concreta el alcance de la primera.

\footnotetext{
9 Vid. Decreto 8/2003, de 30 de junio (BOIB núm. 93, de 1 de julio de 2003); Decretos 26 a 32/2003, de 26 de noviembre (BOIB núm. 170, de 9 de diciembre de 2003); Decreto 33/2003, de 17 de diciembre (BOIB núm. 177, de 25 de diciembre de 2003); Decreto 23/2003, de 17 de octubre (BOIB núm. 148, de 25 de octubre de 2003); Decreto 1/2004, de2 de enero (BOIB núm. 5, de 10 de enero de 2004); Decreto 25/2004, de 10 de septiembre (BOIB núm. 134, de 25 de septiembre de 2004); Decreto 26/2004, de 21 de septiembre (BOIB núm. 136, de 30 de septiembre de 2004); Decreto 14/2005, de 18 de octubre (BOIB núm. 156 ext., de 19 de octubre de 2005).

10 BOIB núm. 104, de 12 de julio d 2007.

11 J. A. Santamaría Pastor, Fundamentos de Derechos Administrativo I. CEURA. Madrid, 1988. Pág. 913.
} 
Por consiguiente debemos concluir que esta distinción carece de toda lógica que la atribución a los órganos que conforman la estructura de una consejería (incluida esta última por tratarse de un órgano administrativo) será de competencias.

\section{C) Organización interna}

El art. 11.c de la Ley 4/2001 se limita a señalar como contenido del instrumento de creación de la consejería su denominación y sus competencias.

No obstante, teniendo en cuenta que el art. 8 de la Ley 3/2003 - relativo a la organización interna de las consejerías - exige que las mismas se estructuren en secretaría general y direcciones generales, y que la estructura orgánica básica de cada consejería debe aprobarse por decreto del presidente del Gobierno de las Illes Balears, habrá que entender forzosamente que este decreto es el instrumento de creación ${ }^{12}$. Dicho con otras palabras, que junto a la denominación y a las competencias, un tercer requisito objetivo en la creación de la consejería será la determinación de su estructura básica, con indicación de las competencias/funciones que se atribuye a cada órgano.

\section{Instrumento de creación}

Hasta ahora las normas que se han examinado aluden a la creación de una consejería por decreto. El término decreto es ambivalente toda vez desde el punto de vista conceptual un decreto puede ser una norma o un acto administrativo.

En efecto decreto es una denominación puramente léxica que no expresa de por sí un significado conceptual.

En su título IV - relativo a las potestades normativas del Gobierno- la Ley 4/2001 dedica su capítulo III a la potestad reglamentaria. El art. 38 de este texto legal atribuye con carácter general la potestad reglamentaria de la Administración de la Comunidad autónoma al Gobierno de las Illes Balears, sin perjuicio - de acuerdo con su párrafo tercero - de que el presidente de la Comunidad dicte reglamentos para la «creación y extinción de consejerías, incluida la modificación de la denominación y de las competencias que les corresponden».

12 En una alarde de sistemática jurídica, bien podría este requisito enumerarse en el art. 11.c de la Ley del Gobierno y no tener que manejar dos textos distintos para una misma acción. 
Por consiguiente la Ley del Gobierno atribuye al decreto de creación la naturaleza jurídica de reglamento. Ahora bien, este mismo precepto también considera rango reglamentario a las órdenes de los consejeros, extremo que en puridad no es rigurosamente cierto.

Si el reglamento es la norma escrita con rango inferior a la ley que emana del Gobierno en el ejercicio de una potestad propia, según la regulación al más alto nivel del art. $97 \mathrm{CE}$, toda vez la potestad reglamentaria es un resabio del principio monárquico, en el Estado democrático esta potestad reglamentaria deberá ser objeto de interpretación restrictiva de ahí que los consejeros no puedan ser titulares de la misma. En este sentido, sólo el consejo de gobierno puede dictar reglamentos.

Por lo que respecta al decreto del presidente del gobierno relativo a la creación de una consejería, no vamos a restarle juridicidad a este instrumento. En el Estado de Derecho ya ha quedado superada la vieja polémica sobre si las normas organizativas formaban parte del ordenamiento jurídico o no. Otra cosa es que deban tener la misma categoría que la norma de general aplicación que es un reglamento.

El decreto de creación de una consejería tampoco es en modo alguno un acto administrativo, pues no se extingue nada más ser dictado. No encaja ni siquiera forzadamente en la definición de Zanobini.

Por consiguiente habrá que concluir que este decreto participa de la naturaleza reglamentaria, sin ser exactamente un reglamento, pero teniendo una innegable vis normativa, toda vez innova el ordenamiento jurídico no con un mandato ad extra, pero sí con un mandato imperativo de obligado cumplimiento.

\section{Nombramiento de los titulares de los órganos}

A continuación, una vez creado el departamento, le sigue el nombramiento del titular de la consejería así como lo propio del resto de órganos administrativos de la organización interna.

\section{A) Consejero}

La Ley de Régimen Jurídico remite en su art. 9.2, por lo que respecta al nombramiento y cese de los consejeros, a la Ley de Gobierno de las Illes Balears. Esta última norma residencia en su art. 11.d, como competencia de dirección, en el presidente del gobierno el nombramiento y separación de los consejeros. 


\section{B) Secretario general y directores generales}

Si la organización interna de las consejerías, de acuerdo con el art. 8 de la Ley $3 / 2003$, se estructura en torno a una secretaría general y una o varias direcciones generales, (estructura, reiteramos, que debe aprobarse en el decreto del presidente sobre la creación de la consejería) habrá que examinar de qué forma se nombran los titulares de tales órganos.

En este sentido el art. 19.12 de la Ley 4/2001 atribuye al Consejo de Gobierno la facultad de nombrar y separar mediante decreto a los altos cargos de la Administración de la Comunidad autónoma, siendo así que el art. 2.2. de la Ley 2/1996, de 19 de noviembre, de incompatibilidades de los miembros del Gobierno y de los altos cargos de la $\mathrm{CAIB}^{13}$ considera altos cargos en su apartado a tanto a los directores generales como a los secretarios generales.

En la misma línea el art. 12 de la Ley 3/2003 entiende que los titulares de los órganos directivos son nombrados libremente por el Gobierno atendiendo a criterios de competencia profesional y de experiencia

Este mismo texto legal concreta en sus artículos 13.2 y 15.2 respectivamente que los secretarios generales y los directores generales son nombrados y separados por decreto del Gobierno de las Illes Balears, a propuesta del titular de la consejería.

\section{C) Declaración de actividades y de bienes y derechos patrimoniales}

De acuerdo con lo previsto en la Ley 2/1996 y en su reglamento de desarrollo - aprobado por Decreto 250/1999, de 3 de diciembre ${ }^{14}$ - los altos cargos (en nuestro caso, consejero, secretario general y directores generales) tienen la obligación de formular, en el plazo improrrogable de un mes desde la toma de posesión, declaración de actividades y declaración de bienes y derechos patrimoniales.

En el primer caso los titulares de los órganos descritos están obligados a declarar todas las actividades que ejercen por sí o mediante sustitución o apoderamiento ante el Registro de intereses y actividades.

En el segundo caso, la declaración de bienes y derechos patrimoniales debe contener, como mínimo:

13 BOCAIB núm. 150, de 5 de diciembre de 1996; BOE n’́m. 48, de 25 de febrero de 1997.

14 BOIB núm. 156, de 16 de diciembre de 1999. 
a) Los bienes, derechos y obligaciones patrimoniales que se posean.

b) Los valores o activos financieros negociables.

c) Las participaciones societarias.

d) El objeto social de las sociedades de cualquier clase en las que tengan intereses.

e) Las sociedades participadas, a su vez, por aquellas en que se tengan participaciones de acuerdo con lo que expresa la letra c, señalando los objetos sociales respectivos.

Ambas declaraciones se reiteran con ocasión del cese, igualmente en el plazo improrrogable de un mes.

\section{Apertura de centro de trabajo}

De acuerdo con la previsión establecida por el Real Decreto Legislativo $1 / 1986$, de 14 de marzo $^{15}$, la apertura de un centro de trabajo exige forzosamente su comunicación a la autoridad laboral en los términos de la Orden del Ministerio de Trabajo y Asuntos Sociales de 6 de mayo de $1988^{16}$, de acuerdo con la redacción operada por Orden del Ministerio de Trabajo y Asuntos Sociales de 29 de abril de $1999^{17}$.

La comunicación se efectúa por cuadruplicado ejemplar en modelo oficial, cumplimentado los datos de identificación del empleador, datos del centro de trabajo como domicilio, actividad a realizar, plantilla, clase de centro de trabajo... y datos de producción y almacenamiento. La documentación se presenta ante la Inspección Provincial de Trabajo y Seguridad Social, dentro de los treinta días siguientes a la apertura del centro de trabajo.

Como medida garantista de los trabajadores que integran la plantilla del departamento, esta comunicación debe acompañarse del Plan de Seguridad Y Salud en el trabajo cuando por las circunstancias especiales sea exigido. De ahí que haya que traer a colación la Ley 31/1995, de 8 de noviembre, de Prevención de Riesgos Laborales ${ }^{18}$, desarrollada por el Real Decreto 1627/1997, de 24 de octubre $^{19}$.

\footnotetext{
15 BOE núm. 73, de 26 de marzo de 1986.

16 BOE núm. 117, de 16 de mayo de 1988.

17 BOE núm. 124, de 25 de mayo de 1999.

18 BOE núm. 269, de 10 de noviembre de 1995.

19 BOE núm. 256, de 25 de octubre de 1997.
} 


\section{DISPONIBILIDAD RESUPUESTARIA}

\section{Rectificación de crédito}

Como excepción al principio de especialidad cualitativa, cuantitativa y temporal de los presupuestos generales, el ordenamiento jurídico prevé el mecanismo de las modificaciones de crédito en función de una variación de los escenarios presupuestarios. Para ello habrá que atender al Texto refundido de la Ley de Finanzas y a la ley de presupuestos generales para cada ejercicio.

El Decreto legislativo 1/2005 contempla en su art. 54 la rectificación de créditos para los casos, entre otros, en que se produzcan reorganizaciones administrativas, al objeto de tramitar los correspondientes expedientes de altas y bajas y, por consiguiente, llevar a cabo la correcta imputación contable de los ingresos y gastos.

En desarrollo del art. 54 de la Ley de finanzas, el art. 9.2 del Decreto 75/2004, de 27 de agosto ${ }^{20}$ reitera esta modificación de crédito.

\section{A) Competencia subjetiva e instrumento de creación}

Ambos preceptos aludidos atribuyen la rectificación de crédito al consejero competente en materia de hacienda y presupuestos.

Por lo que respecta al instrumento de creación, el art. 54 del Decreto legislativo 1/2005 hace referencia a una resolución del consejero, mientras que el art. 9.2 del Decreto 75/2004 alude a acuerdo del consejero

Una vez más aparece la invasión del léxico en la sede conceptual de las instituciones jurídicas. A pesar de que en un caso se habla de resolución y en otro de acuerdo, a nadie escapa que el instrumento con el que el consejero lleva a cabo la rectificación de crédito será un acto administrativo. En cualquier caso, resulta más idónea la denominación de resolución por ser ésta - de acuerdo con el art. 89 de la Ley 30/1992, de 26 de noviembre, de régimen jurídico de las Administraciones Públicas y del procedimiento administrativo común ${ }^{21}-$ el acto administrativo definitivo que pone fin a un procedimiento administrativo.

\section{B) Creación de una sección presupuestaria}

En los términos del art. 35 de la Ley de Finanzas y desarrollado anualmente por orden del consejero competente en materia de hacienda y presupuestos

20 BOIB núm. 122, de 2 de septiembre de 2004.

21 BOE núm. 285, de 27 de diciembre de 1992. 
- por la cual se dictan las normas para la elaboración de los presupuestos generales de la Comunidad autónoma - la estructura del estado de gastos de los presupuestos se vertebra en torno a una cuádruple clasificación: orgánica, funcional, económica y territorial.

Lógicamente la creación de una consejería obliga a alterar la clasificación orgánica de los presupuestos. En este sentido, siendo así que en la clasificación orgánica se agrupan los créditos asignados por secciones presupuestarias, la creación de un departamento conlleva ineludiblemente la creación de una sección presupuestaria con su propio código.

En esta sección se darán de alta las partidas que se hubieran presupuestado en otras secciones y que ahora se residencian en esta consejería. Durante el ejercicio presupuestario vigente estas partidas que se crean en a nueva sección todavía arrastrarán el código de la sección de origen; a la entrada en vigor de la ley de presupuestos generales confeccionada teniendo presente la nueva sección, todas sus partidas ya se denominarán con el nuevo código.

Igualmente cabe señalar que tanto los créditos finalistas (piénsese por ejemplo en un convenio de colaboración que hubiera suscrito la Comunidad a través de la anterior consejería y que comporta unas obligaciones presupuestarias) como los gastos plurianuales que la nueva consejería hereda de otra u otras, también conservarán el código de la sección de procedencia durante toda su vigencia.

\section{C) Gastos de personal}

La creación de la sección presupuestaria conlleva inmediatamente la dotación de fondos para hacer frente a los gastos de personal.

- Altos cargos. En el capítulo I de la nueva sección presupuestaria deberá contabilizarse el gasto de las retribuciones de los altos cargos, que - de acuerdo con el art. 31.5.c del Decreto 75/2004 - se compone de sueldo base, complemento de destino, complemento específico y complemento previsto en el art. 10.3 de la Ley 10/1987, de 29 de diciembre, de presupuestos generales de la Comunidad autónoma para el año $1988^{22}$.

- Resto de efectivos. De la misma manera en el capítulo I de la nueva sección presupuestaria habrá que contabilizar el gasto correspondiente a los efectivos que pasan a integrarse en el nuevo departamento que -en el caso de una redistribución de efectivos - llevará la correspondiente baja en la sección de origen.

22 BOCAIB núm. 163, de 31 de diciembre de 1987. 
- Personal con cargo al capítulo VI. En el caso de inversiones que realice directamente la Administración y sólo si para su exclusiva ejecución sea estrictamente necesaria la utilización de personal temporal no permanente, el art. 33 del Decreto 75/2004 admite que con cargo a los créditos de inversiones se pueda imputar el pago de ese personal.

Habrá que contemplar por consiguiente la posibilidad de que el nuevo departamento herede de la consejería de origen un proyecto de inversión, que se dará de alta en el capítulo VI de la nueva sección y que como tal podrá sufragar. Las inversiones que forman parte de su proyecto, ya sea de inmovilizado, de gastos corrientes o de gastos de personal.

\section{Funcionamiento a través de otros órganos y unidades}

No es infrecuente que la rectificación de crédito se limite a la disponibilidad presupuestaria del gasto que funcionalmente le corresponde ejecutar a la nueva sección y que su organización interna - fundamentalmente los servicios comunes - actúe a través de los órganos y unidades de procedencia.

En efecto la nueva consejería - durante el ejercicio presupuestario en el que se ha creado - tramitará a través de la unidad de gestión económica de la o las consejerías de que se escinde, a efectos de gestión presupuestaria. En este sentido, los gastos se imputarán contablemente a las partidas de la sección nueva con el código de la sección de origen, si bien se tramitarán por medio de la unidad de la sección de origen.

En este sentido la creación de una consejería lleva aparejado un reglamento que regula la gestión de los créditos presupuestarios para el ejercicio vigente afectados por la modificación de la estructura orgánica de los presupuestos de la Comunidad autónoma y la creación del nuevo departamento, sobre la base del art. 38.1 de la Ley 4/2001 y del art. 11.g,h,i,j de la Ley 3/2003 ${ }^{23}$.

\section{A) Ejecución presupuestaria}

En este punto se distingue entre la ejecución y gestión del presupuesto de ingresos y la autorización, disposición, reconocimiento de la obligación y propuesta de pago de gastos por un lado, y la propuesta de las diversas fases de la gestión de ingresos, de la gestión de gastos y de modificaciones de crédito, por otro.

23 Vid. el Decreto 114/2005, de 28 de octubre, por el que se regula la gestión de los créditos presupuestarios del ejercicio 2005 afectados por las modificaciones de la estructura orgánica de los presupuestos de la comunidad autónoma y la creación de la Consejería de Inmigración y Cooperación. BOIB núm. 165, de 3 de noviembre de 2005. 
En el primer caso, tales actos para la nueva consejería corresponden al consejero en el que se residencien las mismas de acuerdo con la distribución presupuestaria que se determina en el decreto de creación de la consejería. Por el contrario, las propuestas de las fases de la gestión de ingresos y gastos y las modificaciones de crédito corresponden a los órganos que tengan atribuidas tales funciones según el decreto de creación del nuevo departamento y el decreto o decretos de modificación de la estructura orgánica básica de las consejerías de origen, siendo así que cualquier conflicto en la distribución de créditos será resuelto por el consejo de Gobierno.

Esta distinción tiene una consecuencia práctica fundamental, y es que la modificación de la estructura orgánica de la consejería de origen y la creación del nuevo departamento no se traduce en variaciones en las aplicaciones presupuestarias vigentes de la primera.

\section{B) Gastos de personal}

Por lo que respecta a los gastos de personal, resulta obligado distinguir entre la nómina de los altos cargos y el resto del personal de nueva creación por un lado, y los efectivos que se redistribuyen al nuevo departamento, por otro.

En el primer caso, los gastos de personal de los altos cargos y del resto de personal de nueva creación (fundamentalmente el personal eventual) se imputan a la nueva sección presupuestaria que se da de alta en la estructura orgánica del presupuesto de gastos de la Comunidad, en el concepto económico servicios nuevos.

Por el contrario y por lo que se refiere a los efectivos del antiguo departamento que pasan a prestar servicios en la nueva consejería como consecuencia de un procedimiento de redistribución de efectivos, sus retribuciones, las cuotas de la Seguridad Social y cualquier régimen de revisión social se siguen abonando con cargo a los programas presupuestarios de la antigua consejería hasta la entrada en vigor del presupuesto para el ejercicio siguiente.

\section{C) Función interventora y gestión económica}

Hasta la entrada en vigor de la ley de presupuestos para el siguiente ejercicio presupuestario, la función interventora y la gestión económica relativas a los actos o expedientes de la nueva consejería, tanto de gestión del presupuesto de gastos como del de ingresos, las siguen ejerciendo las mismas unidades que las ejercían con anterioridad a la creación del nuevo departamento.

Tales funciones corresponden a las unidades de gestión económica, que son unidades administrativas dependientes del órgano secretaría general Con ello 
quiere decirse que la gestión y la tramitación de los expedientes de ingresos, pero fundamentalmente de gastos, se llevan a cabo en las UGEs de las secretarías de las consejerías de origen ${ }^{24}$.

\section{D) Contabilización liquidación del presupuesto}

La contabilización y la liquidación del presupuesto del ejercicio vigente se lleva a cabo en las mismas secciones, centros gestores y programas presupuestarios establecidos en el presupuesto inicialmente aprobado, con independencia de las modificaciones de atribución de funciones que afecten a la estructura orgánica de los órganos adscritos a las consejerías.

\section{RECURSOS HUMANOS}

\section{Cambio de adscripción de puestos de trabajo}

\section{A) Escisión de un departamento}

La creación de una consejería por escisión de otro departamento conlleva una modalidad de la redistribución de efectivos que consiste en el traslado de un puesto de trabajo (con el funcionario incluido) al nuevo órgano. En este sentido, el cambio de adscripción del puesto de trabajo supone dar de baja ese puesto en la RPT de la consejería de origen y dar de alta ese mismo puesto con sus mismas características de nivel, complemento específico, forma de provisión... en el nuevo departamento.

El art. 31.3 de la Ley 3/2007 contempla este supuesto y prevé que la modificación de una RPT se haga automáticamente siempre que sea como consecuencia de una reestructuración orgánica, requiriendo únicamente la aprobación del Consejo de Gobierno y su publicación.

En desarrollo de este precepto el art. 91 del mismo texto legal - relativo al cambio de adscripción del puesto de trabajo - reitera que el Consejo de Gobierno, a propuesta del consejero competente en materia de función pública, por reestructuración de la Administración o por necesidades del servicio, pueda acordar la adscripción de puestos de trabajo y del personal que los ocupa a tras consejerías y a las entidades públicas dependientes.

24 Sobre la creación y funciones de las UGEs, vid. el Decreto 20/1985, de 28 de marzo. BOCAIB núm. 11, de 20 de abril de 1985 . 
Una vez efectuada la adscripción, los datos se comunican al Registro General de Personal en los términos del art. 42 de la Ley 3/2007 y del Decreto 46/1995, de 4 de mayo ${ }^{25}$.

\section{B) Traspaso de competencias}

No hay que descartar la constitución de un órgano administrativo como consecuencia de un traspaso de competencias procedente de otra Administración. En este caso la ley de transferencia determina - junto a los medios materiales (inmuebles, vehículos...) y presupuestarios - la relación de efectivos que se transfiere y que pasan a integrar la plantilla de personal del departamento que los recibe.

Igualmente en este supuesto habrá que modificar la RPT según el procedimiento del art. 31 de la Ley 3/2007.

Debe señalarse en este punto que el personal que se transfiere pertenece a un cuerpo de funcionarios de la Administración de procedencia (si es un traspaso a la CAIB, será del Estado). Desde el momento en que se hace efectiva la transferencia, su situación administrativa en la Administración de origen es la de servicios en otras Administraciones Públicas (art. 88 de la Ley 7/2007, de 12 de abril, del Estatuto Básico del Empleado Público ${ }^{26}$ ) y en la CAIB pasarían a ocupar sus puestos de trabajo en servicio activo, correspondiéndoles las condiciones de trabajo previstas para los empleados públicos de la CAIB.

Estos efectivos podrán acceder a los cuerpos, escalas y especialidades de la Administración autonómica por la vía de la integración, de acuerdo con el art. 27.b de la Ley 3/2007 y el régimen de movilidad interadministrativa que contempla el Capítulo V del Título VII de la misma norma.

\section{Creación de puestos de trabajo}

Teóricamente la creación de una consejería, ya sea por escisión de otro departamento, o bien como consecuencia de un traspaso de competencias, no debería repercutir en un aumento total del número de efectivos de una Administración, sino que debería ordenarse con criterios de racionalidad y lógica, distribuyendo en órganos y unidades el mismo número de efectivos que con anterioridad se concentraban en un solo órgano.

No obstante, no hay que descartar que la creación de una consejería conlleve la creación de puestos de trabajo, fundamentalmente del personal eventual que acompaña al titular de la consejería.

\footnotetext{
25 BOCAIB núm. 61, de 13 de mayo de 1995.

26 BOE núm. 89, de 13 de abril de 2007.
} 
En este caso el art. 29 de la Ley 3/2007 en su punto tercero determina que la creación de puestos de trabajo se lleve a cabo mediante la modificación de la RPT correspondiente, de suerte que una vez más habrá que estar al procedimiento que contempla el art. 31 de la misma norma, siendo fundamentales los informes de las direcciones generales competentes en materia de función pública y presupuestos.

\section{Orden de funciones}

\section{A) Concepto y naturaleza jurídica}

Con carácter general el art. 6.6 de la Ley 3/2003 determina que el inicio del funcionamiento de nuevas unidades previstas en la RPT sólo será efectivo cuando se hayan señalado reglamentariamente las funciones que deben desarrollar.

En el mismo sentido, el art. 8.3 de esta misma norma contempla que los consejeros, mediante orden, deben desarrollar la estructura orgánica básica, de acuerdo con la RPT vigente, al objeto de determinar las funciones atribuidas a las unidades administrativas de cada consejería.

La orden de funciones - como manifestación de la potestad organizatoria y de dirección de la Administración - se concibe en el art. 34 de la Ley 3/2007 como un instrumento técnico de ordenación mediante el cual la Administración asigna las funciones a los puestos de trabajo.

\section{B) Procedimiento}

El procedimiento de elaboración de la orden de funciones coincide con el general reglamentario regulado en la sección segunda del capítulo tercero, Título IV, de la Ley 4/2001, con las particularidades que contempla la Instrucción $3 / 2003$, de 12 de noviembre, de la directora general de función pública, por la que se fijan los criterios para la confección de las órdenes de funciones de los puestos de trabajo del personal funcionario de las diferentes consejerías ${ }^{27}$, fundamentalmente informe previo de la consejería competente en materia de función pública.

Otra salvedad consiste en la innecesariedad de contar con dictamen del Consell Consultiu, dado que se trata de una disposición meramente organizativa y así se exceptúa en el art. 10.6 de la Ley 5/1993, de 15 de junio ${ }^{28}$.

27 BOIB núm. 165, de 27 de noviembre de 2003.

28 BOCAIB núm. 83, de 8 de julio de 1993. BOE núm. 197, de 18 de agosto de 1993. 
Por consiguiente el procedimiento de elaboración de la orden de funciones discurre por los siguientes pasos:

1. Orden del consejero por el que encomienda a la secretaría general de la consejería la elaboración de la orden de funciones.

2. Memoria justificativa del secretario general sobre la necesidad de elaborar la orden.

3. Estudio económico del secretario general, por el que se certifica que la orden carece de efectos económicos.

4. Redacción del borrador del proyecto de orden.

5. Remisión del borrador a los órganos afectados.

6. Informe de la dirección general competente en materia de función pública.

7. Redacción definitiva del proyecto de orden y remisión al BOIB.

\section{PROCEDIMIENTO ADMINISTRATIVO}

\section{Creación del registro de entrada y salida de documentos}

Como órgano administrativo que es, una consejería deberá contar necesariamente con un registro para hacer efectivo el derecho de los ciudadanos a presentar escritos y documentos.

La LRJCAIB contempla en su art. 37 el derecho de presentación de escritos y documentos, si bien guarda silencio respecto de las oficinas de registro.

Habrá que acudir por ello por la vía de la supletoriedad al art. 38 LRJPAC y a su normativa complementaria, fundamentalmente el real Decreto 772/1999, de 7 de mayo, modificado por el Real Decreto 209/2003, de 21 de febrero. Quedará a voluntad del consejero crear registros telemáticos en los términos del Decreto 14/2007, de 9 de marzo, por el que se regulan los registros telemáticos y las notificaciones telemáticas de la Administración de la CAIB $^{29}$.

En la Comunidad autónoma de las Illes Balears el registro se configura como un sistema informático único, común a toda la Administración, con subapartados por consejerías, de suerte que cada consejería cuenta con un código de dos dígitos.

29 BOIB núm. 39, de 15 de marzo de 2007. 


\section{Régimen de suplencias}

La ocupación de un cargo por su titular - ya sea el de consejero o el de un órgano directivo - pese a ser definitiva y permanente, puede que no se ejerza temporalmente por razones de vacante, ausencia o enfermedad. Para estos casos el ordenamiento jurídico prevé la institución de la suplencia, regulada en el art. 17 LRJPAC, los art. 32 y 33 LRJCAIB y los art. 11.f y 17.2 de la Ley $4 / 2004$.

En los términos del art. 32 LRJCAIB, debe señalarse que la suplencia se limita al despacho ordinario y a la tramitación de los actos que son competencia, propia o delegada, del órgano cuyo titular se sustituye; que las suplencias se pueden establecer para un ámbito general o específico, así como para supuestos concretos; y que la designación de suplentes debe publicarse en el BOIB, excepto de la que corresponda a supuestos concretos. Por último, se admite que coexistan distintas suplencias de un mismo titular, trayendo a colación el principio de especialidad: se entiende que la de ámbito específico prevalece sobre la de ámbito general, y ambas pueden quedar en suspenso si se establece una suplencia para un supuesto concreto.

\section{A) Entre miembros del Gobierno}

Una de las funciones de dirección que la Ley 4/2004 atribuye al presidente en su art. 11.f consiste en la determinación mediante decreto de las suplencias de los consejeros y del vicepresidente, en su caso, en los supuestos de ausencia, enfermedad o en los casos de abstención obligada.

Normalmente este decreto es el inmediatamente posterior al decreto por el cual se establece la estructura del Gobierno ${ }^{30}$.

\section{B) Secretaría del Consejo de Gobierno}

De las sesiones del consejo de Gobierno - según el art. 17 de la Ley 4/2004 - debe extenderse acta por un secretario del mismo, en la que debe constar como mínimo, además de las circunstancias relativas al tiempo, lugar y asistentes, las decisiones y los acuerdos adoptados. Al secretario del consejo de Gobierno le corresponde - en los términos del art. 7.2.d del Decreto $132 / 2002$, de 25 de octubre ${ }^{31}$ - ordenar la publicación de los acuerdos aprobados por este órgano y la publicación de las órdenes que afecten a más de una consejería.

30 Vid. Decreto 5/2004, de 23 de enero (BOIB núm. 17, de 3 de febrero de 2004).

31 BOIB núm. 132, de 2 de noviembre de 2002. 
La secretaría del consejo de Gobierno se designa en el decreto por el que se determina la composición del Gobierno, sin perjuicio de normativa complementaria ${ }^{32}$.

La misma incidencia de vacante, ausencia o enfermedad puede verificarse igualmente en el ejercicio de esta función, de manera que - al tiempo que se asigna la secretaría a un consejero- deberá preverse la suplencia de éste en los términos del art. 17.2 de la Ley 4/2004, suplencia que es independiente del régimen de suplencia del consejero que ejerce la secretaría del consejo de Gobierno en sus funciones propias de la consejería de la que es titular ${ }^{33}$.

\section{C) Órganos directivos}

De conformidad con lo previsto en el art. 33 LRJCAIB, la suplencia de los titulares de los órganos directivos se lleva cabo de la siguiente forma:

a) Los secretarios generales, los directores generales y el resto de órganos directivos se suplen por el órgano directivo que determine el consejero.

b) Si no se ha designado expresamente un suplente, el secretario general suple a los directores generales, y - en caso de no existir- el director general más antiguo en el cargo o, si dos o más tiene la misma antigüedad, el de mayor edad.

c) Si no existe designación expresa, el director general más antiguo en el cargo suple al secretario general o, si dos o más tienen la misma antigüedad, el de mayor edad.

d) En el resto de casos la suplencia la debe determinar el superior jerárquico del titular del órgano afectado entre los titulares de órganos del mismo rango o del rango inmediatamente inferior. Si no existe designación expresa, los suple el superior jerárquico.

Esta previsión normativa tiene por objeto regular la suplencia en caso de que no haya sido prevista en el seno de la consejería respectiva. No es infrecuente que el propio titular de la consejería - en uso de las atribuciones que le confiere el art. 38.2.a de la Ley 4/2004- regule por orden los supuestos de vacante, ausencia o enfermedad.

\section{Delegación de competencias y delegación de firma}

El ordenamiento jurídico residencia en los consejeros competencias de gestión tanto en materia de personal como presupuestaria.

32 Vid. Decreto 88/2007, de 20 de julio (BOIB núm. 112, de 21 de julio de 2007), de modificación del Decreto 70/2007, de 12 de julio (BOIB núm. 105, de 13 de julio de 2007).

33 Vid. art. 3 del Decreto 9/2007, de 6 de julio (BOIB núm. 101 ext, de 9 de julio de 2007) y art. 3 del Decreto 6/2003, de 30 de junio (BOIB núm. 93, de 1 de julio de 2003). 
En efecto, el art. 11.d LRJCAIB - en consonancia con el art. 4.2 de la Ley $3 / 2007$ - atribuye a los consejeros la facultad de «dirigir los recursos humanos de la consejería, de acuerdo con la legislación específica». En línea con este precepto el art. 7 de la Ley 3/2007 permite la delegación de competencias del consejero competente en materia de función pública en el resto de consejeros, de acuerdo con los límites propios de la delegación (art. 25 LRJCAIB y art. 13 LRJPAC).

En otro orden de cosas el art. 11 LRJCAIB en sus apartados g, h e i y el art. 9 del Decreto legislativo 1/2005 en sus apartados b, c y d atribuyen al consejero las funciones de:

- gestionar los créditos para gastos de sus secciones presupuestarias y proponer sus modificaciones;

- autorizar y disponer los gastos que no sean de la competencia del Consejo de Gobierno elevarle la aprobación de las que le correspondan;

- reconocer las obligaciones económicas y proponer su pago.

En ambos casos resulta obligado señalar que estas funciones exigen una celeridad y una agilidad en su gestión y tramitación que el consejero no siempre puede garantizar dada su función representativa, que absorbe propiamente la de dirección y gestión.

De ahí que con frecuencia y con carácter inmediatamente posterior a la creación de la consejería, el titular de la misma resuelva la delegación de la competencia en materia del personal dependiente de la consejería en el secretario general, así como la delegación de la firma en el mismo responsable de los servicios generales de los documentos contables y administrativos de autorización y disposición de gastos, y de reconocimiento de obligaciones, en los términos de los artículos 25 y 31 LRJCAIB, respectivamente, en conexión con los artículos 13 y 16 LRJPAC.

En uno y en otro caso la delegación se efectúa por resolución del consejero, haciéndose constar la circunstancia de la delegación y la autoridad de procedencia. La delegación de competencias exige publicidad oficial a tenor de lo dispuesto en el art. 27 LRJCAIB.

En este punto debería plantearse por qué en un caso se delega la competencia y en otro se delega exclusivamente la firma. Ni la LRJCAIB ni el Decreto legislativo 1/2005 atribuyen a los actos del consejero en materia de ejecución presupuestaria su carácter de indelegables, como sí formula respecto de otras funciones. Tampoco la Ley 3/2007 atribuye al consejero competencias en materia de función pública si no se las delega el consejero competente en esta materia en los términos de su art. 7. 
¿Por qué entonces se delega en el secretario general la competencia en materia de personal y en cambio sólo se le delega la firma en materia presupuestaria? Quizás haya que acudir, para responder a esta pregunta, a las competencias del secretario general que enumera el art. 14 de la Ley 3/2003.

En efecto, en su apartado f este precepto atribuye al secretario general «gestionar, bajo la dirección del consejero, los recursos humanos de la consejería»; en cambio, en su apartado d residencia en este órgano la función de «controlar, bajo la dirección superior del consejero, la gestión del presupuesto de la consejería». Por consiguiente, la LRJCAIB permite al secretario general una intervención mayor en materia de personal que en sede presupuestaria.

A pesar, como decimos, de que la Ley de Función Pública no atribuya al consejero competencias en esta materia, lo cierto y verdad es que el consejero es el responsable de la gestión ordinaria del personal de su consejería no atribuida a tros órganos ${ }^{34}$. Y siendo así que el secretario general es el órgano directivo encargado de la gestión de los servicios comunes según el art. 13 LRJCAIB, no es de extrañar que al mismo se le deleguen las competencias en materia de personal.

Por el contrario, dado que la gestión presupuestaria se atribuye en la LRJCAIB y en la legislación específica al consejero, y dado que la función del secretario general en este punto es más limitada, se le delega exclusivamente la firma.

\section{Bases reguladoras de subvenciones}

Una manifestación de la actividad administrativa de fomento consiste en la concesión de subvenciones. Para ello y de conformidad con la ley de subvenciones, resulta indispensable que cada departamento cuente con unas bases reguladoras de las subvenciones que otorga en el marco del plan estratégico de subvenciones aprobado por el Consejo de Gobierno.

La creación de una consejería no siempre exige la elaboración de unas bases, sino que la nueva consejería - si importa de otro departamento una competencia material - podrá convocar una subvención de acuerdo con las bases reguladoras de la consejería de origen en función de la materia de que se trate. Incluso es perfectamente posible que una consejería que absorbe materias de más de un departamento, se regulen por distintas bases, tantas como consejerías de procedencia. Otra cosa es que con el tiempo, estas bases dispersas se acaben refundiendo en una sola orden y se elaboren las bases nuevas que han de regir la convocatoria de subvenciones del nuevo departamento.

34 Vid. Miguel Sánchez Morón, Derecho de la Función Pública. Tecnos. Madrid, 1996. Págs. 98 y 99. 
En efecto, el art. 12.1 del Decreto legislativo 2/2005, de 28 de diciembre, por el que se aprueba el Texto refundido de la Ley de ubvenciones, enumera los supuestos en los que no resulta obligado contar con una orden de bases reguladoras de subvenciones:

a) Cuando las normas sectoriales específicas de la subvención incluyan las bases reguladoras con el contenido mínimo que exige el art. 13 del mismo texto legal;

b) Cuando los beneficiarios sean entidades locales y la subvención se conceda en ejecución de instrumentos de planificación aprobados previamente por la Administración de la Comunidad autónoma, siendo así que estos instrumentos de planificación sustituyen a las bases reguladoras y por ello deben ser objeto de publicación;

c) Cuando las subvenciones deriven de convenios formalizados entre administraciones públicas o entidades de derecho público dependientes, con la finalidad de regular el otorgamiento de subvenciones a favor de terceras personas. En estos casos los convenios pueden sustituir a las bases reguladoras si así lo prevén expresamente y son objeto de publicación oficial.

d) Las subvenciones que se conceden directamente al margen de los principios de publicidad y concurrencia que contempla el art. 7 de este texto legal, con las particularidades propias del procedimiento para estos casos

\section{A) Plan estratégico de subvenciones}

El Decreto legislativo 2/2005 exige en su art. 12.2.b que las bases reguladoras de subvenciones se adecuen al plan estratégico de subvenciones. Este precepto trae causa del art. 6 del texto refundido de la Ley de subvenciones, según el cual por acuerdo del consejo de gobierno, a propuesta del consejero competente en materia de hacienda y presupuestos, deben aprobarse uno o varios planes estratégicos de subvenciones, de acuerdo con la información y las propuestas que presenten las consejerías y las entidades de derecho público dependientes, salvo las de concesión directa y las diseñadas por la Unión Europea, el Estado u otro ente público cuya gestión corresponda, total o parcialmente, a la Administración de la Comunidad autónoma.

Según este mismo precepto los planes deben concretar, como mínimo, al alcance temporal, los objetivos y los efectos que se persiguen, los plazos de consecución, los costes previsibles y las fuentes de financiación, todo ello dentro del marco de los objetivos de estabilidad presupuestaria y de la programación presupuestaria plurianual. Asimismo los planes deben especificar la incidencia eventual sobre el mercado de los objetivos que se pretendan conseguir y, en su caso, la orientación de estos objetivos hacia la corrección de los errores que se identifiquen para que la distorsión del mercado sea mínima. 
El art. 6 del Decreto legislativo 2/2005 se encuentra en directa relación con el art. 8 de la Ley de Cortes Generales 38/2003, de 17 de noviembre ${ }^{35}$, básico para todas las Comunidades autónomas.

El plan estratégico forma parte de los mecanismos de planificación y control que contempla el texto refundido (registro de subvenciones...).

\section{B) Contenido de las bases}

De acuerdo con el art. 13 del Decreto legislativo 2/2005, las bases reguladoras de la concesión de subvenciones deben determinar, como mínimo, los siguientes aspectos:

a) La definición del objeto de la subvención que exprese la finalidad de utilidad pública o social a que se destina la subvención;

b) La compatibilidad o incompatibilidad de la subvención con las ayudas que pueda obtener el beneficiario de la misma administración o de otra entidad pública o privada. En caso de compatibilidad deberá ajustarse a los límites contemplados en el art. 20 de este texto legal.

c) Los requisitos generales que deben cumplir los beneficiarios de la subvención, la forma de acreditarlos y, en su caso, el período durante el cual deben mantenerse.

d) Los criterios objetivos que, con carácter general, han de regir el otorgamiento de la subvención y, en su caso, la ponderación.

e) Las reglas generales para la determinación del importe de la subvención, como también, en su caso, la exigencia de financiación propia para cubrir la actividad subvencionada.

f) Los órganos competentes para la iniciación, instrucción y resolución del procedimiento, así como la existencia o no de comisión evaluadora.

g) Las reglas generales sobre los plazos y las prórrogas, así como, en su caso, la obligación de comunicar a la Administración el inicio de la actividad subvencionada y el momento en que este puede comenzar.

h) Las obligaciones específicas de los beneficiarios y de las entidades colaboradoras, en su caso.

i) Las condiciones de solvencia que han de cumplir las personas jurídicas que puedan actuar como entidades colaboradoras

35 BOE núm. 276, de 18 de noviembre de 2003. 
j) Las condiciones generales para el pago de la subvención, como también la posibilidad de realizar pagos fraccionados y/o pagos anticipados y el régimen general de las garantías que, en su caso, se deban exigir a los beneficiarios, sin perjuicio del régimen jurídico de los pagos anticipados que contempla el art. 37 del mismo texto legal.

k) Las reglas generales sobre la forma de justificar, por parte del beneficiario o de la entidad colaboradora, del cumplimiento de la finalidad para la cual se concede la subvención y de la aplicación de los fondos percibidos, tanto por lo que respecta al gasto realizado como, en su caso, al pago de éste.

1) El plazo durante el cual el beneficiario debe destinar los bienes al fin concreto para el que se concede la subvención, en su caso, de acuerdo con el art. 40.4.a de esta misma norma.

m) Las medidas de garantía a favor de los intereses públicos que, en su caso, se consideren necesarias, así como, en su caso, los supuestos específicos que pueden dar lugar a la revocación de la subvención.

n) Los criterios de graduación de los posibles incumplimientos de las condiciones impuestas con motivo de la concesión de la subvención y que, de conformidad con el principio de proporcionalidad, han de servir para fijar la cuantía que finalmente deba percibir el beneficiario o, en su caso, el importe que deba reintegrar.

o) Los mecanismos que aseguren la publicidad de las subvenciones de cuantía inferior a 3000,00 euros, de conformidad con lo que prevé el art. 34.2.c de este misma norma.

\section{C) Procedimiento de elaboración de las bases}

Las bases se aprueban por orden del consejero, de manera que habrá que estar en este punto a lo previsto en los artículos 42 a 47 de la Ley 4/2001, con las particularidades que contempla el art. 12.2 del Decreto legislativo 2/2005:

a) El estudio económico a que se refiere el art. 42.1 de la Ley 4/2001 debe suscribirlo la secretaría general de la consejería correspondiente y se debe pronunciar sobre la suficiencia de recursos económicos, previstos o previsibles, al efecto de prever las disponibilidades presupuestarias que permitan dicta, en su caso, el acto de convocatoria regulado en el art. 15 del Decreto legislativo $2 / 2005$.

b) Debe adjuntarse al anteproyecto de orden un informe de la dirección general competente en materia de presupuestos relativo a la adecuación del anteproyecto al plan estratégico de subvenciones aplicable. 
En particular, la elaboración de las bases exige los siguientes actos de trámite:

1. Orden del consejero por el que encomienda a la secretaría general de la consejería la elaboración de la orden reguladora de las bases que han de regir las subvenciones de la consejería.

2. Memoria justificativa del secretario general sobre la necesidad de elaborar la orden.

3. Estudio económico del secretario general.

4. Redacción del borrador del proyecto de orden.

5. Remisión del borrador a los presidentes de los Consejos insulares, a los alcaldes de todos los municipios de las Illes Balears, al resto de consejerías y a los agentes económicos y sociales relacionados por razón de la materia.

6. Remisión del proyecto al BOIB a efectos de información pública.

7. Segundo borrador de orden en función de las alegaciones efectuadas.

8. Remisión del proyecto de orden al Presidente de la CAIB a efectos de su sometimiento a dictamen del Consell Consultiu, en los términos del art. 10.6 de la Ley 5/1993, de 15 de junio.

9. Dictamen del Consell Consultiu.

10. Informe de la dirección general competente en materia de presupuestos.

11. Memoria económica de la orden firmada por el secretario general de la consejería.

12. Redacción definitiva del proyecto de orden y remisión al BOIB. 